\title{
CARACTERIZAÇÃO DE UMA FRAÇÃO RICA EM ATIVIDADE COBALTO-ATPÁSICA DE CÉREBRO BOVINO
}

Characterization of a fraction rich in cobalt-atpasic activity in bovine brain

Caracterización de una fracción rica en la actividad cobalta-atpásica en el cerebro bovino

\section{Hugo Christiano Soares Melo*1, Decivaldo dos Santos Dias ${ }^{2}$, Milton Vieira Coelho ${ }^{3}$}

${ }^{1}$ Faculdade Patos de Minas (FPM), Patos de Minas, Brasil.

${ }^{2}$ Secretaria de Estado de Educação, Cultura e Esporte (Seduce), Goiânia, Brasil.

${ }^{3}$ Universidade Federal de Uberlândia (UFU), Instituto de Genética e Bioquímica (INGEB) - Uberlândia, Brasil.

*Correspondência: Faculdade Patos de Minas (FPM) - Av. Juscelino Kubitschek de Oliveira, $n^{o} 1220$, Bairro

Cristo Redentor, Patos de Minas, MG, Brasil - CEP 38706-401.e-mail: hugo.some@gmail.com

\section{RESUMO}

As ATPases (Adenosina Trifosfatases) são enzimas que hidrolisam ATP para obter energia e realizar algum tipo de trabalho na célula. Esse artigo caracterizou a atividade ATPásica de uma fração obtida a partir de cérebro bovino utilizando o protocolo de obtenção de miosina $\mathrm{V}$ de cérebro de rato. A fração obtida apresentou alta atividade ATPásica com $\mathrm{Mg}^{+2}(100 \%)$ e com $\mathrm{Co}^{2+}(95 \%)$. Valores inferiores foram encontrados com cálcio (50\%), zinco (40\%), cobre $(15 \%)$ e ferro (10\%). As curvas cinéticas de concentração de cátions sugerem que o sítio catalítico da enzima

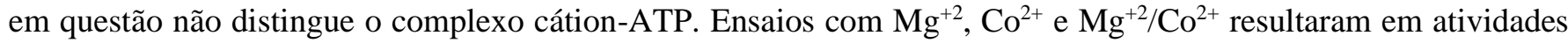
ATPásicas praticamente iguais, o que descarta a presença de enzimas distintas. O comportamento enzimático dessa fração é distinto da descrita no método original, indicando que a enzima encontrada na fração de cérebro de rato (miosina V) é diferente da enzima encontrada em cérebro de boi, ou apenas que o sítio catalítico desta funciona de modo distinto da primeira.

Palavras-chave: Bovino; Encéfalo; Cobalto; ATPase.

\section{ABSTRACT}

ATPases (Adenosine Triphosphatases) are enzymes that hydrolyze ATP to obtain energy and perform some type of work in the cell. This article characterized the ATPasic activity of a fraction obtained from bovine brain using the rat brain myosin V protocol. The fraction obtained showed high ATPásica activity with $\mathrm{Mg}^{+2}(100 \%)$ and $\mathrm{Co}^{2+}(95 \%)$. Lower values were found with calcium (50\%), zinc (40\%), copper (15\%) and iron (10\%). The kinetic curves of cation concentration suggest that the catalytic site of the enzyme in question does not distinguish the cation-ATP complex. Tests with $\mathrm{Mg}^{+2}, \mathrm{Co}^{2+}$ and $\mathrm{Mg}^{+2} / \mathrm{Co}^{2+}$ resulted in nearly equal ATPasic activities, which rules out the presence of distinct enzymes. The enzymatic behavior of this fraction is different from that described in the original method, indicating that the enzyme found in the rat brain fraction (myosin $V$ ) is different from the enzyme found in ox brain, or just that its catalytic site works in a different way from first.

Keywords: Bovine; Brain; Cobalt; ATPase.

\section{RESUMEN}

Las ATPasas (trifosfatasas de adenosina) son enzimas que hidrolizan el ATP para obtener energía y realizar algún tipo de trabajo en la célula. Este artículo caracterizó la actividad ATPasic de una fracción obtenida del cerebro bovino usando el protocolo de miosina $V$ de cerebro de rata. La fracción obtenida mostró una alta actividad ATPásica con $\mathrm{Mg}^{+2}$ (100\%) y $\mathrm{Co}^{2+}$ (95\%). Se encontraron valores más bajos con calcio (50\%), zinc (40\%), cobre 
(15\%) y hierro (10\%). Las curvas cinéticas de la concentración de cationes sugieren que el sitio catalítico de la enzima en cuestión no distingue el complejo catión-ATP. Las pruebas con $\mathrm{Mg}^{+2}, \mathrm{Co}^{2+} \mathrm{y} \mathrm{Mg}^{+2} / \mathrm{Co}^{2+}$ resultaron en actividades ATPasic casi iguales, lo que descarta la presencia de enzimas distintas. El comportamiento enzimático de esta fracción es diferente del descrito en el método original, lo que indica que la enzima encontrada en la fracción de cerebro de rata (miosina $V$ ) es diferente de la enzima encontrada en el cerebro de buey, o simplemente que su sitio catalítico funciona de manera diferente a primero.

Descriptores: Bovina; Cerebro; Cobalto; ATPasa.

\section{INTRODUÇÃO}

As ATPases (Adenosina Trifosfatases) são enzimas que catalisam a quebra de ATP em ADP e Pi (fosfato inorgânico), geralmente acopladas com um sistema capaz de aproveitar a energia dessa hidrólise (Komoszynski \& Wojtczak, 1996). As ATPases podem ser divididas em duas classes principais, as ATPases de membrana e as ATPases solúveis. Dentre as ATPases de membrana temos por exemplo as transportadoras de íons (geralmente definidas como Ptype ATPases) como as $\mathrm{Ca}^{2+}$-ATPases que estão envolvidas na regulação da concentração de $\mathrm{Ca}^{2+}$ intracelular (Carafoli, 1997), e as $\mathrm{Na}^{+} / \mathrm{K}^{+}$-ATPases que realizam o transporte ativo de sódio e potássio pela membrana visando criar um potencial de ação (Lingrel \& Kuntzweiler, 1994). As ATPases solúveis compreendem algumas ecto-ATPases que podem quebrar tanto nucleotídeos tri como difosfato (Plesner, 1995), e os chamados motores moleculares, que utilizam a energia da quebra do ATP para realizar movimento (Schliwa \& Woehlke, 2003; Melo et al., 2006).

É característica da maioria das ATPases também, utilizarem alguns cátions como cofatores (como o íon $\mathrm{Mg}^{+2}$ por exemplo) que complexam com o ATP facilitando sua hidrólise, ou ainda em diversos sistemas biológicos, em adição à $\mathrm{Na}^{+} / \mathrm{K}^{+}$e $\mathrm{Ca}^{+2}$ ATPases (que transportam seus respectivos íons através da membrana), a presença de transportadores de metais de transição às custas da energia do ATP, como o descrito por Barañano et al. (2000), que indica um processo onde um transportador associado à membrana seria a ligação entre o catabolismo de grupos heme, que liberam íons ferrosos, pela heme oxygenase-1 (HO1), e a liberação de ferro celular. Gunshin (1997) ainda descreve um novo transportador de íons metálicos em rato, DCT1, o qual apresenta um extenso e não usual espectro de substratos, que incluem $\mathrm{Fe}^{2+}, \mathrm{Zn}^{2+}, \mathrm{Mn}^{2+}, \mathrm{Co}^{2+}$, e outros. Podemos citar ainda uma ATPase exportadora de metais chamada de CoaT, cuja ação detalhada ainda permanece obscura apesar de que mutação nos genes que codificam tal transportador já indicou intolerância ao cobalto, a despeito de resistência normal a outros metais (Cavet et al, 2003). Além disso, já se conhece também um grupo de genes chamado de CoaT operador-promotor que é ativado dependentemente de cobalto por uma proteína chamada de CoaR, fazendo com que se inicie a transcrição de CoaT (Rutherford et al, 1999).

Diversos autores ainda descrevem situações onde ainda não se tem a evidência de transporte de metais envolvidos, no entanto diversos metais modulam a hidrólise do ATP, funcionando como cofatores ou apenas como reguladores, como SouzaSantos et al. (2001) que descrevem a inibição de 8090\% da atividade ATPásica de $\mathrm{H}^{+}$-ATPase de raiz de milho pela presença de íons ferro, tanto no seu estado ferroso quanto férrico, em concentrações de 100 a 200 $\mu \mathrm{M}$, comprovada pela ação de quelantes metálicos como o EDTA que foi capaz de evitar a inibição da atividade ATPásica. Também foi descrito, por Lippe et al. (2002), um sítio específico para ligação de íons ferro, na subunidade $\beta$ da F1-ATPase mitocondrial, 
cuja reação de oxidação deste íon com $\mathrm{H}_{2} \mathrm{O}_{2}$ causa inativação desta enzima por dano direto à proteína. Cool et al. (2002) descreveu a presença de hidrólise de ATP de proteína associada à resistência multidrogas (human multidrug resistance-associated protein, MRP1) tanto na presença de magnésio quanto de cobalto. Morsomme et al. (2002) ao caracterizar uma ATPase expressa em levedura (MJ1226p ATPase) encontrou atividade $\mathrm{Co}^{2+}$-ATPásica maior que $\mathrm{Mg}^{2+}$ ATPásica, numa relação de 6:10 de ATP para o íon correspondente. Ainda cloreto de cobalto $\left(\mathrm{CoCl}_{2}\right)$ conseguiu evitar a inibição da atividade $\mathrm{Na}^{+}-\mathrm{K}^{+}-$ ATPase renal, pela inibição da atividade do citocromo P450, cujos metabólitos são conhecidos reguladores do transporte de sódio no rim (Zhang et al, 1997).

Um dos mais importantes metais de transição de diversos sistemas biológicos é o cobalto, que atua como ativador para colinesterase, carboxilase e fofoglicomutase, e ainda possui uma proteção da respiração do cérebro contra alta pressão de oxigênio (Mcdonalad \& Phillips, 1963) além de participar da síntese de cobalaminas, dentre elas, a vitamina B12 (Stangl et al, 1999). São conhecidas duas rotas de síntese de vitamina B12, uma chamada de anaeróbica e outra aeróbica, distintas pelos passos de inserção do cobalto, onde a via anaeróbica não necessita de ATP e o passo de inserção é paralelo ao passo de inserção de ferro na formação do grupo heme, e a via aeróbica requer ATP, paralelamente à inserção de magnésio na clorofila (Williams \& Silva, 2000). Sabe-se que as principais enzimas em que a vitamina B12 age como cofactor são a metilmalonil-CoA mutase [EC 5.4.99.2] e a metionina sintase [EC 2.1.1.13] (Stangl et al, 1999), embora estudos com estruturas de raios X com os domínios de ligação da cianocobalamina nestas enzimas ainda não tenham solucionado o problema do mecanismo de ativação enzimática das mesmas (Marques \& Brown, 2002).
Nosso grupo obteve uma fração enriquecida em atividade ATPásica a partir de fração solúvel de cérebro de rato, cuja análise em "Western Blotting" mostrou uma banda que reagiu especificamente com anticorpo anti-miosina $\mathrm{V}$ e a presença de cloreto de cobalto II não afetou a atividade $\mathrm{Mg}^{2+}$-ATPásica (Soares Melo, 2007). Este mesmo método levou ao isolamento de uma fração rica em atividade $\mathrm{Ca}^{2+}$ ATPásica e com dois principais polipetídeos identificados como miosina e actina através de MALDI-TOF MS (Soares Melo, 2018). Este trabalho buscou caracterizar a atividade ATPásica encontrada em cérebro bovino, a partir deste mesmo protocolo, e comparar os aspectos enzimáticos das duas frações.

\section{MATERIAIS E MÉTODOS}

\section{Fracionamento do homogeneizado de cérebro de boi}

Cérebros bovinos foram fornecidos por frigoríficos da região, e colocados em gelo em no máximo 5 minutos após o abatimento. Frações de 100g de cérebro foram separadas e homogeneizadas em 120 $\mathrm{mL}$ de tampão contendo Imidazol-HCl $50 \mathrm{mM}$ pH 8,0, EDTA $10 \mathrm{mM}$, EGTA $10 \mathrm{mM}$, sacarose $25 \mathrm{mM}$, DTT $1 \mathrm{mM}$, benzamidina $1 \mathrm{mM}$, aprotinina $1 \%(\mathrm{v} / \mathrm{v})$ e calpastatina $1 \mu \mathrm{L} / \mathrm{mL}$. Essa fração foi centrifugada a 45000 x g por 40 minutos gerando uma fração solúvel S1 e uma precipitada P1. Essa fração solúvel era estocada a $-20^{\circ} \mathrm{C}$ em frascos de plásticos com capacidade de $25 \mathrm{~mL}$ e a fração precipitada descartada. No início de cada experimentação, a fração $\mathrm{S} 1$ era descongelada em banho com água a temperatura ambiente, centrifugada a $45000 \mathrm{x}$ g por 40 minutos formando duas frações S2 e P2. A fração P2 era ressuspensa em $10 \mathrm{~mL}$ de tampão padrão contendo imidazol-HCl 20 mM pH 7,5, EDTA 0,1 mM e DTT 0,1 mM. Essa fração P2 era então novamente centrifugada a $45000 \mathrm{x}$ g por 40 minutos resultando 
nas frações S3 e P3. P3 era então ressuspenso em $5 \mathrm{~mL}$ do tampão EDTA 1 mM e DTT 0,1 mM.

\section{Determinação da atividade atpásica}

A atividade ATPásica foi determinada pela quantificação do fosfato inorgânico (Pi) liberado pela hidrólise de ATP, usando o método colorimétrico de Heinonen \& Lahtti (1981), que dosa a formação do complexo fosfomolibdato a partir de molibdato de amônio, onde a cor amarela formada é lida em espectofotômetro em absorbância de $355 \mathrm{~nm}$.

Os ensaios foram feitos a $37^{\circ} \mathrm{C}$ em duplicatas com volume final de $200 \mu \mathrm{L}$, onde o meio de reação usado continha Imidazol $\mathrm{HCl} 25 \mathrm{mM}$ pH 7,5, DTT $1 \mathrm{mM}$, EDTA $1 \mathrm{mM}, \mathrm{KCl} 60 \mathrm{mM}$, na presença dos respectivos cátions: $\mathrm{MgCl}_{2} 4 \mathrm{mM}, \mathrm{CaCl}_{2} 2 \mathrm{mM}$ ou $\mathrm{CoCl}_{2} 2 \mathrm{mM}$. A reação foi iniciada pela adição de 1 $\mathrm{mM}$ de ATP, e interrompida pela adição de $2 \mathrm{~mL}$ de solução de dosagem AAM (preparada a partir de dois volumes de acetona P.A., um de molibdato de amônio $100 \mathrm{mM}$ e um de ácido sulfúrico $5 \mathrm{~N}$ ), sendo o conteúdo agitado por cerca de 15 segundos em vórtex seguido da adição de $200 \mu \mathrm{L}$ de ácido cítrico 1M, cuja função é encerrar a reação do ensaio, complexando com possíveis Pi resultantes da hidrólise de ATP após o fim da incubação e impedindo portanto que o molibdato complexe com esses $\mathrm{Pi}$ e aumente falsamente a tonalidade da cor amarela, seguindo por nova agitação de cerca de 10 segundos. Como padrão, foi feita uma curva utilizando-se ortofosfato $\left(\mathrm{KH}_{2} \mathrm{PO}_{4}\right)$, com concentrações que variavam de $0 \mathrm{a}$ $250 \mathrm{nM}$.

\section{RESULTADOS E DISCUSSÃO}

A fração P3 obtida de cérebro bovino possui alta atividade ATPásica, na presença não apenas do cátion $\mathrm{Mg}^{+2}$ (100\%), mas também do cátion $\mathrm{Co}^{2+}$ (95\%), sugerindo que esta fração pode empregar tanto cátion magnésio quanto cobalto II complexados com
ATP como substrato. Na presença de cátions divalentes dos elementos cálcio e zinco esta fração apresentou uma capacidade intermediaria em realizar a hidrólise do ATP, enquanto que para os cátions bivalentes de cobre e ferro observou-se uma menor atividade ATPásica desta fração. As atividades de hidrólise do ATP foram respectivamente 50\%, 40\%, $15 \%$ e $10 \%$ da capacidade apresentada pelo cátion magnésio (Fig. 1).

Figura 1: Atividade ATPásica de P3 na presença de diferentes cátions divalentes. Quinze microgramas de P3 foram incubados a $37^{\circ} \mathrm{C}$ por 10 minutos em presença de cátions cálcio, magnésio, zinco, cobre, cobalto e ferro 2 $\mathrm{mM}$.

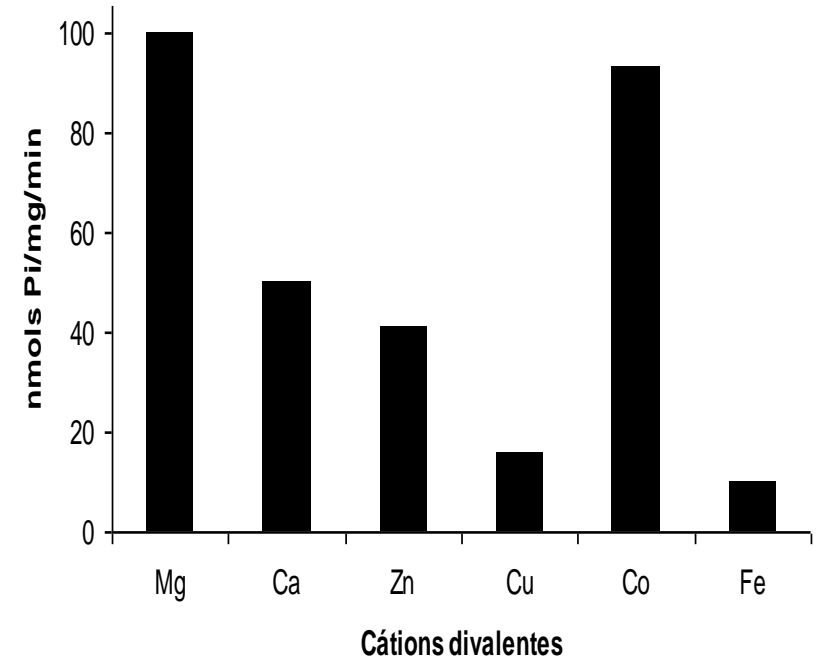

Diversos autores têm descrito algumas similaridades entre as propriedades físico-químicas de cátions divalentes principalmente entre os aqui citados. Há similaridade na interação íon metálicopolímero sendo esta basicamente eletrostática $(\mathrm{Ge}$, 2017). Complexos bivalentes dos cátions cobalto, cobre, zinco com 4dimethylaminocinnamylidenepyruvate mostram grau de hidratação e estabilidade térmica parecidos como demonstrado por Schnitzler et al. (2002) além de semelhante estado cristalino amorfo. Complexos aminados de Cobalto II mimetizam o complexo $\mathrm{Mg}+2$ ATP em sítios enzimáticos da $\mathrm{Na}^{+} / \mathrm{K}^{+}$-ATPase não obstante não serem hidrolisados (Schoner et al, 1998) 
enquanto que também Cini et al. (1983) mostram semelhança na coordenação geométrica do complexo formado por estes cátions com ATP. Ruth-Gomis et al. (1994) também descrevem a astacina, uma metaloproteinase, sensível aos cátions divalentes de cobalto, cobre, zinco. Destes trabalhos podemos entender que há alguma similaridade entre os cátions $\mathrm{Mg} 2+, \mathrm{Ca}^{2+}, \mathrm{Mn}^{2+} \mathrm{e} \mathrm{Co}^{2+}$, quando complexados com ATP. E ainda segundo o trabalho de Cini et al. (1983), a geometria do complexo $\mathrm{Mg}^{2+}$-ATP é extremamente semelhante com a do complexo $\mathrm{Co}^{2+}-\mathrm{ATP}$, trazendo certa justificativa aos dados aqui encontrados, no caso de os dois complexos estarem disputando o mesmo sítio catalítico.

Várias ATPases bem caracterizadas, como miosina II requerem cátions magnésio para originar o substrato adequado complexo $\mathrm{Mg}^{2+}$-ATP. Quanto a ATPases dependentes do cátion cobalto II não se têm caracterizações bem descritas em literatura. Com base na presença de atividade $\mathrm{Mg}^{+2}$-ATPásica e $\mathrm{Co}^{2+}$ ATPásica, e na ausência de descrições sucintas e detalhadas sobre a segunda atividade, ainda que Cool et al. (2002) e Morsomme et al. (2002) tenham encontrado atividades $\mathrm{Co}^{2+}$-ATPásica em seus estudos, nossa primeira impressão foi a presença de contaminantes nas soluções, ou mesmo na amostra. No entanto ao analisarmos as curvas de variação da concentração de cátions, pela atividade ATPásica, tivemos total certeza da não contaminação em nossos ensaios. Analisamos a concentração de $\mathrm{Mg}^{+2}$ (Fig. 2), $\mathrm{Ca}^{+2}$ (Fig. 3) e $\mathrm{Co}^{2+}$ (Fig. 4), obtendo em todas as curvas um comportamento sigmóide e uma concentração ótima (maior atividade ATPásica) do respectivo cátion, por volta de $2 \mathrm{mM}$, não obstante as atividades $\mathrm{Ca}^{2+}$-ATPásica e $\mathrm{Co}^{2+}$-ATPásica máximas foram de $70 \%$ e $83 \%$ quando comparadas com a atividade $\mathrm{Mg}^{+2}$-ATPásica quando a concentração de ATP era fixa e de $1 \mathrm{mM}$.
Figura 02: Atividade ATPásica de $\mathrm{P} 3$ frente a cátions Magnésio. Quinze microgramas de P3 foram incubados a $37^{\circ} \mathrm{C}$ por 10 minutos com concentrações diversas de íons magnésio.

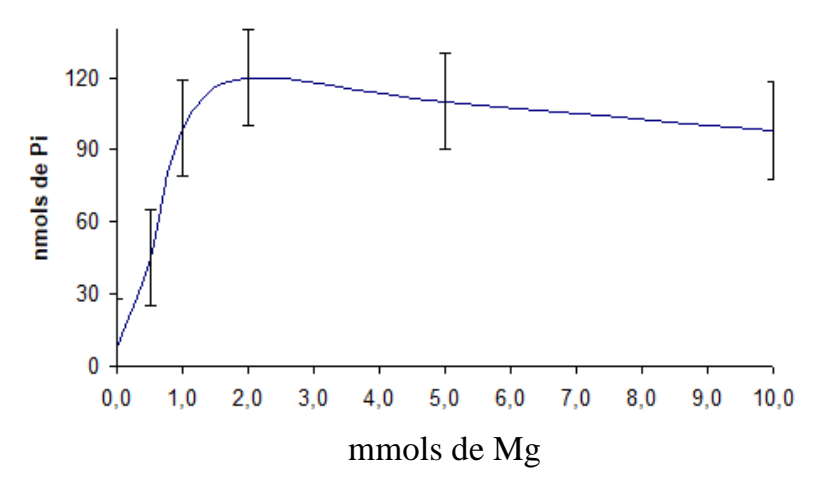

Figura 03: Atividade ATPásica de P3 frente a cátions Cálcio. Quinze microgramas de $\mathrm{P} 3$ foram incubados a $37^{\circ} \mathrm{C}$ por 10 minutos com concentrações diversas de íons cálcio.

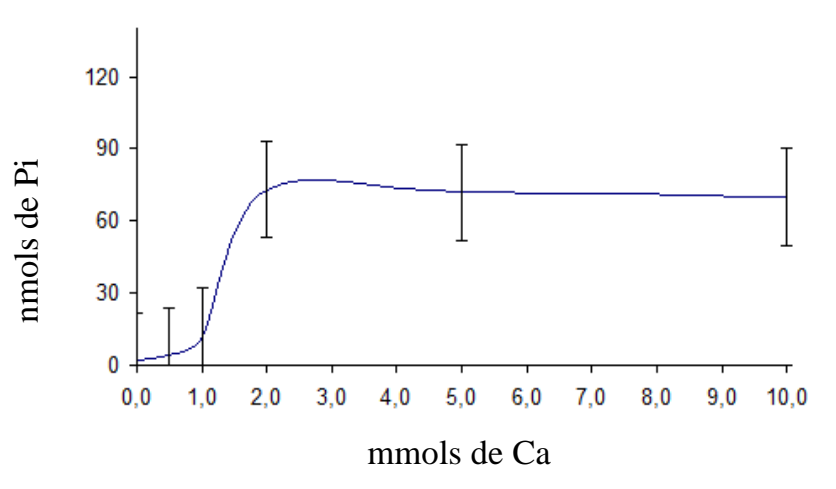

A concentração que gera a máxima velocidade catalítica foi em torno de $2 \mathrm{mM}$ e que $1 / 2$ da velocidade máxima é atingida em concentração próxima de 1,25 mM. sugerindo a presença de uma única ATPase na fração P3. Este resultado pode significar que o sítio catalítico da enzima presente em P3, apesar de mostrar alta especificidade na maioria dos casos, no nosso caso não distingue eficientemente o complexo cátion-ATP, podendo ser ele $\mathrm{Mg}^{+2}-\mathrm{ATP}$ ou $\mathrm{Co}^{+2}-\mathrm{ATP}$, que estariam a competir pelo mesmo sitio de ligação da enzima ATPásica. Ainda, temos a informação de que o complexo com ATP ótimo para nossa enzima está na presença de dois cátions para um ATP.

Figura 04: Atividade ATPásica de P3 frente a cátions Cobalto II. Quinze microgramas de P3 foram incubados a $37^{\circ} \mathrm{C}$ por 10 minutos em presença de cátion cobaltoso em concentrações diversas. A reação foi iniciada pela adição de 
$1 \mathrm{mM}$ de ATP e, interrompida pela adição de $2 \mathrm{~mL}$ de solução de dosagem.

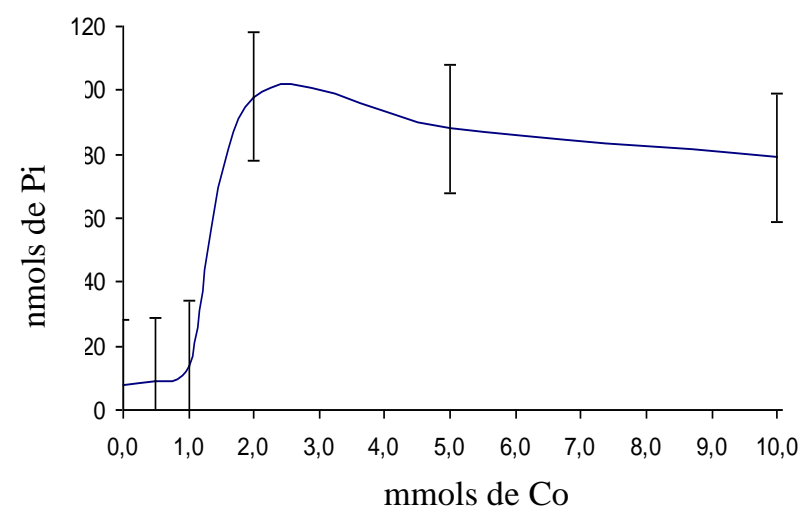

Outra possibilidade para explicar as hidrólises realizadas tanto em presença de cátions cobalto II quanto em presença de cátions magnésio seria a presença de duas enzimas ATPásicas na nossa fração P3. Uma delas seria responsável pela atividade $\mathrm{Mg}^{+2}$ ATPásica e outra pela atividade $\mathrm{Co}^{2+}$-ATPásica. Nesse sentido testamos a atividade ATPásica de nossa fração na presença de tanto, íons $\mathrm{Mg}^{+2}$ quanto de íons $\mathrm{Co}^{2+}$ (Fig. 5), que na presença de duas ATPases distintas, deveriam apresentar atividade ATPásica de praticamente o dobro do encontrado para um íon somente, uma vez que as duas enzimas estariam trabalhando juntas. Novamente encontramos resultados que mostraram um caminho diferente. As atividades na presença de $\mathrm{Mg}^{+2}, \mathrm{Co}^{2+}$ e $\mathrm{Mg}^{+2} / \mathrm{Co}^{2+}$ foram praticamente iguais, indicando que há somente uma única enzima capaz de hidrolisar o ATP em nossa fração, apesar de que esta pode utilizar o ATP tanto complexado com $\mathrm{Mg}^{+2}$ quanto com $\mathrm{Co}^{2+}$, reforçando a ideia de que estes estão em competição pelo sítio catalítico da enzima.

Figura 05: Efeito do Cobalto e Magnésio na atividade ATPásica de P3. Quinze microgramas de P3 foram incubados a $37^{\circ} \mathrm{C}$ por 10 minutos com Cloreto de Magnésio ou Cloreto de Cobalto II, 2 mM, conforme indicado.

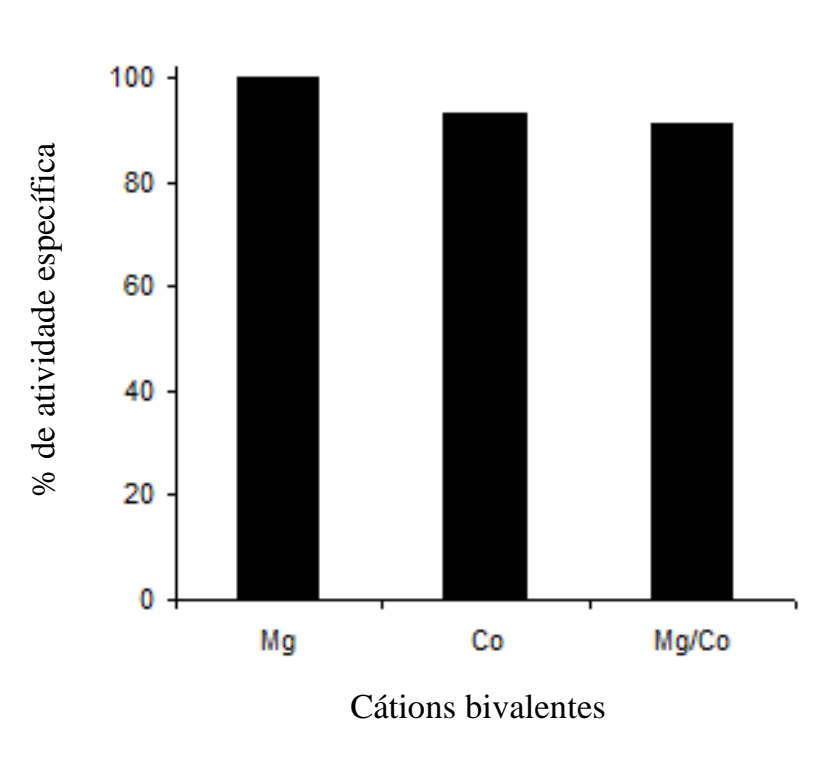

\section{CONCLUSÃO}

A atividade ATPásica da fração isolada de cérebro bovino mostra-se diferente das encontradas pelo mesmo método em cérebros de rato e por isso deve-se buscar o sequenciamento e identificação desta fração para que mais semelhanças e diferenças catalíticas possam ser feitas a respeito dessas frações obtidas de diferentes tecidos e espécies.

\section{AGRADECIMENTO}

Esta pesquisa foi suportada por projeto $\mathrm{N}^{\circ}$ CBB 285697 da FAPEMIG (Fundação de Amparo à Pesquisa do Estado de Minas Gerais - Brazil). O presente trabalho foi realizado com apoio da Coordenação de Aperfeiçoamento de Pessoal de Nível Superior - Brasil (CAPES) - Código de Financiamento 001.

Todos os autores declararam não haver qualquer potencial conflito de interesses referente a este artigo.

\section{REFERÊNCIAS}

BARANANO, D. E.; WOLOSKER, H.; BAE, B. I.; BARROW, R. K. et al. A mammalian iron ATPase induced by iron. J Biol Chem, 275, n. 20, p. 1516615173, May 192000. 
CARAFOLI, E. Plasma membrane calcium pump: structure, function and relationships. Basic Res Cardiol, 92 Suppl 1, p. 59-61, 1997.

CAVET, J. S.; BORRELLY, G. P. M.; ROBINSON, N. J. Zn, $\mathrm{Cu}$ and $\mathrm{Co}$ in cyanobacteria: selective control of metal availability. FEMS Microbiology Reviews 27, p. 16, 2003.

CINI, R.; SABAT, M.; SUNDARALINGAM, M.; BURLA, M. C. et al. Structural studies on metal-ATP complexes: x-ray structures of $\mathrm{Mg}(\mathrm{II}), \mathrm{Ca}(\mathrm{II}), \mathrm{Mn}(\mathrm{II})$ and $\mathrm{Co}$ (II) ternary complexes with ATP and dipyridylamine. Inorganica Chimica Acta, 79, p. 2, 1983.

COOL, R. H.; VEENSTRA, M. K.; KLOMPENBURG, W. v.; HEYNE, R. I. R. et al. SDecyl-glutathione nonspecifically stimulates the ATPase activity of the nucleotide-binding domains of the human multidrug resistance-associated protein, MRP1 (ABCC1). Eur. J. Biochem., 269, p. 18, 2002.

GE, J.; HUANG, F.; NESMELOV, Y. E. Metal cation controls phosphate release in the myosin ATPase. Protein Science, 26, n. 11, p. 5, 2017.

GOMIS-RÜTH, F. X.; KRESS, L. F.; KELLERMANN, J.; MAYR, I. et al. Refined $2 \cdot 0 \AA$ $\mathrm{X}$-ray Crystal Structure of the Snake Venom Zincendopeptidase Adamalysin II: Primary and Tertiary Structure Determination, Refinement, Molecular Structure and Comparison with Astacin, Collagenase and Thermolysin. Journal of Molecular Biology, 239, n. 4, p. 513-544, 1994/06/16/ 1994.

GUNSHIN, H.; MACKENZIE, B.; BERGER, U. V.; GUNSHIN, Y. et al. Cloning and characterization of a mammalian proton-coupled metal-ion transporter. Nature, 388, n. 6641, p. 482-488, Jul 311997.

HEINONEN, J. K.; LAHTI, R. J. A new and convenient colorimetric determination of inorganic orthophosphate and its application to the assay of inorganic pyrophosphatase. Analytical Biochemistry, 113, n. 2, p. 313-317, 1981/05/15/ 1981.

KOMOSZYNSKI, M.; WOJTCZAK, A. Apyrases (ATP diphosphohydrolases, EC 3.6.1.5): function and relationship to ATPases. Biochim Biophys Acta, 1310, n. 2, p. 233-241, Feb 21996.

LINGREL, J. B.; KUNTZWEILER, T. Na+,K(+)ATPase. J Biol Chem, 269, n. 31, p. 19659-19662, Aug 51994.

LIPPE, G.; DI PANCRAZIO, F.; CONTESSI, S.; BORTOLOTTI, N. et al. The nucleotide-independent
Fe(III)-binding site is located on $\beta$ subunit of the mitochondrial F1-ATPase. Biochemical and Biophysical Research Communications, 297, n. 3, p. 587-592, 2002.

MARQUES, H. M.; BROWN, K. L. Molecular mechanics and molecular dynamics simulations of porphyrins, metalloporphyrins, heme proteins and cobalt corrinoids. Coordination Chemistry Reviews 225, p. 36, 2002.

MCDONALD, C. C.; PHILLIPS, W. D. A Nuclear Magnetic Resonance Study of Structures of Cobalt (II)-Histidine Complexes. J. Chem. Phys., 85, p. 7, 1963.

MORSOMME, P.; CHAMI, M.; MARCO, S.; NADER, J. et al. Characterization of a hyperthermophilic P-type ATPase from Methanococcus jannaschii expressed in yeast. J Biol Chem, 277, n. 33, p. 29608-29616, Aug 162002.

PLESNER, L. Ecto-ATPases: identities and functions. Int Rev Cytol, 158, p. 141-214, 1995.

RUTHERFORD, J. C.; CAVET, J. S.; ROBINSON, N. J. Cobalt-dependent transcriptional switching by a dual-effector MerR-like protein regulates a cobaltexporting variant CPx-type ATPase. J Biol Chem, 274, n. 36, p. 25827-25832, Sep 31999.

SCHLIWA, M.; WOEHLKE, G. Molecular motors. Nature, 422, p. 759-765, 2003.

SCHNITZLER, E.; LAZZAROTTO, M.; CARVALHO-FILHO, M. A. D. S.; IONASHIRO, M. Thermoanalytical study of the complexes of 4dimetilaminocinnamylidenepiruvate with manganese (ii), cobalt (ii), nickel (ii), cupper (ii), zinc (ii) and lead (ii), in the solid state. Eclética Química Journal, 27, n. $1,2002$.

SCHONER, W.; MERTENS, W.; HELMS, M.; FORTES, G. Binding of the Co(NH3)4 derivative of (2')3'-O-[N-methyl-anthraniloyl]-ATP to the E2ATP site of $\mathrm{Na}+\mathrm{K}+$-transporting ATPase lowers the conformational flexibility of its E1ATP site. Eur J Biochem, 253, n. 1, p. 245-250, Apr 11998.

SOARES MELO, H. C.; LACERDA, R. F.; DIAS, D. d. S.; CRUZ, G. C. N. d. Motores moleculares. Ciência Hoje, 39, n. 230, p. 6, 2006.

SOARES MELO, H. C.; COELHO, M. V. A new method to precipitate myosin $\mathrm{v}$ from rat brain soluble fraction. Acta Biochim Pol, 54, n. 3, p. 575-581, 2007. 
SOARES MELO, H. C.; CRUZ, G. C. N. d.; SOUSA, M. V. d.; COELHO, M. V. Identification and characterization of $\mathrm{p}$. nucleorum larvae myosin. International Journal of Recent Scientific Research, 9, n. 8, p. 7, 2018.

SOUZA-SANTOS, P. C.; RAMOS, R. S.; FERREIRA, S. T.; CARVALHO-ALVES, P. C. Ironinduced oxidative damage of corn root plasma membrane H+ATPase. Biochimica et Biophysica Acta (BBA) - Biomembranes, 1512, n. 2, p. 357-366, 2001/06/06/ 2001

STANGL, G. I.; SCHWARZ, F. J.; KIRCHGESSNER, M. Cobalt deficiency effects on trace elements, hormones and enzymes involved in energy metabolism of cattle. Int J Vitam Nutr Res, 69, n. 2, p. 120-126, Mar 1999.

WILLIAMS, R. J. P.; SILVA, J. J. R. F. d. The distribution of elements in cells. Coordination Chemistry Reviews, 200, n. 202, p. 102, 2000.

ZHANG, Y. B.; MAGYAR, C. E.; HOLSTEINRATHLOU, N.-h.; MCDONOUGH, A. A. The Cytochrome P-450 Inhibitor Cobalt Chloride Prevents Inhibition of Renal Na,K-ATPase and Redistribution of Apical NHE-3 During Acute Hypertension. Journal of the American Society of Nephrology, 9, n. 4, p. 6, 1997. 